\title{
Erratum to: A multi-institutional study of the impact of open textbook adoption on the learning outcomes of postsecondary students
}

\author{
Lane Fischer $^{1} \cdot$ John Hilton III ${ }^{1}$ T. Jared Robinson ${ }^{2}$. \\ David A. Wiley ${ }^{3}$
}

Published online: 2 January 2016

(C) Springer Science+Business Media New York 2015

\section{Erratum to: J Comput High Educ (2015) 27:159-172 DOI 10.1007/s12528-015-9101-x}

Unfortunately, the complete Conflict of Interest statement was missing in the published article. The complete statement is as follows: The first three authors of this paper (Lane Fischer, John Hilton III, and T. Jared Robinson) have no conflict of interest in the execution or outcomes of this study. The fourth author, David A. Wiley, is Chief Academic Officer at Lumen Learning, Portland, Oregon. Lumen Learning offers services to institutions that are transitioning from commercial textbooks to open educational resources. Dr. Wiley, previously at Brigham Young University, Provo, Utah, joined Lumen Learning after the research was

The online version of the original article can be found under doi:10.1007/s12528-015-9101-x.

Lane Fischer

lane_fischer@byu.edu

John Hilton III

johnhiltoniii@byu.edu

T. Jared Robinson

t.jared.robinson@gmail.com

David A. Wiley

david.wiley@gmail.com

1 Brigham Young University, 340-E MCKB, Provo, UT 84602, USA

2 Michigan State Department of Education, Lansing, MI, USA

3 Lumen Learning, Portland, OR, USA 
conceptualized and as it was being conducted. While Lumen Learning has received funding from the Bill and Melinda Gates Foundation, the Gates Foundation grant that supported this research went entirely to Brigham Young University. 